\title{
Is Diabetes Responsible for an Increase of the Mean Red Cell Volume?
}

\begin{abstract}
Dear Sir,
The Short Communication of Davidson et al. [1] deserves some comment: The authors, who reported a higher mean red cell volume (MCV) in a group of 100 diabetic patients compared with a control group, were asking other investigators to contribute to the understanding of this result.

We would like to make the following suggestions based on studies that we have carried out. We studied the MCV values in two populations of normal subjects (485 men in the first study [2], 995 men and women in the second one [3]), and we found in both cases a significant increase of $\mathrm{MCV}$ related to alcohol and tobacco consumption. The regression equations drawn from the second study showed that a difference of $\mathrm{MCV}$ value under $2 \mathrm{cu} \mu \mathrm{m}$, as observed by Davidson et al. in Aberdeen, might be due to relatively small differences in alcohol intake and/or smoking habits between the two groups. Thus, the small differences reported by Davidson et al. in the group of women are consistent with our findings. Unfortunately no data were given on alcohol and smoking habits.

In addition, we were somewhat puzzled by the total absence of information regarding the control group. Hence, it was probably insufficient simply to exclude those subjects known to have an excessive alcohol intake. It would be necessary to perform further studies in order to assess precisely the possible effects of alcohol and smoking habits on MCV values. We are attempting to do this in our studies on diabetic subjects in order to throw further light on this interesting observation.
\end{abstract}

Yours sincerely

L. Papoz, J. M. Warnet and E. Eschwege

\section{References}

1. Davidson RJL, Evan-Wong LA, Stowers JM (1981) The mean red cell volume in diabetes mellitus. Diabetologia 20:583-584

2. Eschwege E, Papoz L, Lellouch J, Claude JR, Cubeau J, Pequignot G, Richard JL, Schwartz D (1978) Blood cell and alcohol consumption with special reference to smoking habits. J Clin Pathol 31:654-658

3. Papoz L, Warnet JM, Pequignot G, Eschwege E, Claude JR, Schwartz D (1981) Alcohol consumption in a healthy population. J Am Med Assoc 245: 1748-1751

L. Papoz and E. Eschwege

Unité de Recherches Statistiques

INSERM

16 bis, Avenue Paul-Vaillant-Couturier

F-94800 Villejuif, France

J. M. Warnet

Laboratoire de la Direction des

Affaires Sanitaires et Sociales

F-75 Paris, France

\section{More About Carbohydrates}

\section{Dear Sir,}

Dr. Reaven [Diabetologia 20: 508-509] reiterates his statement that 'recommendations leading to major modifications in the kind of carbohydrate and fat in the diabetic diet must be based upon sound experimental data' - an unexceptionable statement, except that he implies that we must not advise a change in anyone's eating habits, whether the local norm is $40 \%$ of total calories from carbohydrate or $75 \%$. If we are to wait for 'sound experimental data' in terms of clinical end points (morbidity and/or mortality) we may wait until the 21 st century or for ever. Taking a stand upon the status quo is hardly more satisfactory. In terms of the average, carbohydrate consumption has changed enormously in Europe and North America during this century; in Britain average consumption of carbohydrate as a proportion of total calories is still declining. Nobody recommended these changes; nor were they the out- come of experimental studies. They happened as a result of diverse economic forces. The average also hides a variety of individual behaviour. Thus in one of our population studies the range of individual carbohydrate intake was from $10-65 \%$.

Currently, a billion or so of the World's inhabitants habitually consume a diet high in polysaccharide carbohydrate and low in total fat, a form of dietary practice which is associated with low rates of atherosclerosis. There is a great deal of evidence from several disciplines, not only epidemiology, which supports the thesis that this diet is a major, though clearly not the only, factor determining the low rates of atherosclerotic disease. Against this Dr. Reaven counters with a few thousand Pima Indians, quoting from two papers concerned with (1) coronary heart disease and (2) diet in that population. Ingelfinger et al. [1] reported that coronary heart disease, judged by the prevalence of $Q$ waves in the ECG, was substan- 
tially more frequent in men in the Pima population. We also observed this in the Pima diabetic sample in the WHO Multinational Study. The Pima male diabetics in that study had an average prevalence of $\mathrm{Q}$ wave abnormalities almost exactly the average of the men in the whole study (14 populations), whereas the Pima women diabetics were near the low end of the distribution. These data are more recent than those reported by Ingelfinger et al. and has the added advantage that all ECGs for the international comparisons were coded by the same pair of observers. Thus, it is arguable that the Pima are in a transitional state, the men, if not the women, moving towards a higher incidence of coronary heart disease. Incidentally, $Q$ wave abnormality rates in the Oklahoma Indian diabetics in the WHO study were, in both sexes, amongst the highest observed. The dietary data which Dr. Reaven quotes are based upon women only and were restricted to the age group $25-44$ years. It is certainly true that the fat intake was similar to the US average and that total cholesterol levels were, on average, relatively low. However, these women have a phenomenally high frequency of gall bladder disease and the role of vagaries of cholesterol metabolism in this population has been only partly explored.

The one thing that all diabetics get is advice or recommendations concerning diet. Those involved in treating patients cannot sit back and wait for those further studies which Dr. Reaven wants. They have to have a policy for 1981. Total calorie intake can only be determined by experience with the individual diabetic. The distribution of these calories is a policy matter and I agree with that outlined in the letter of Dr. Mann and his colleagues (Diabetologia 20:507-508),-i.e. 'for the majority of diabetics the diet could safely contain $55 \%$ of carbohydrate calories provided that it was high in dietary fibre and low in simple sugar'. I would add that most of the general population would be better off on such a diet.

Yours sincerely,

R. J. Jarrett

\section{References}

1. Ingelfinger JA, Bennett PH, Liebow IM, Miller M(1976) Coronary heart disease in the Pima Indians; Electrocardiographic findings and postmortem evidence of myocardial infarction in a population with a high prevalence of diabetes mellitus. Diabetes 25:561-565

2. Reid JM, Fullmer SD, Pettigrew KD, Burch TA, Bennett PH, Miller M, Whedon GD (1971) Nutrient intake of Pima Indian women: relationships to diabetes mellitus and gallbladder disease. Am J Clin Nutr 24: 1281-1289

\section{R. J. Jarrett}

Department of Community Medicine

Guy's Hospital Medical School

London Bridge

London SE1 9 RT, UK

\section{Renal Collagen Glucosyltransferase Activity Following Islet Transplantation in Streptozotocin-Diabetic Rats}

\begin{abstract}
Sir,
In a recent article in Diabetologia, Chang et al. [1] reported increased renal galactosyl-hydroxylysine-glucosyltransferase (EC 2.4.1.66) activity in diabetic Chinese hamsters, using a modification of the assay system recently described by Draeger and Weithmann [2]. Spiro and Spiro [3] were the first to report elevated renal activity of this collagen basement membrane enzyme in alloxan-diabetic rats, suggesting that this reflected increased basement membrane synthesis in diabetes mellitus; with insulin therapy, the enzyme activity returned to normal in some cases. Other workers, however, could not confirm these findings [4] and studies in streptozotocindiabetic rats have given controversial results [5-7].

We have therefore determined the glucosyltransferase activity using the recently described assay system [2] in 12 age-matched normal rats, seven diabetic and seven islet-transplanted diabetic rats of the same inbred strain (Lewis/Han). For this study a moderate diabetes (mean fasting blood glucose value about $14 \mathrm{mmol} / \mathrm{l}$ ) was induced at the age of 4 months by IV injection of streptozotocin $65 \mathrm{mg} / \mathrm{kg}$. Six weeks after induction of diabetes islet transplantation was performed in seven rats as previously described [8]. The remaining seven diabetic rats and 12 normal rats served as controls. All animals were killed following pentobarbital anaesthesia at age 12-15 months. Part of one kidney was used for histological exami-
\end{abstract}

nation as described earlier [8]. The remaining tissue and the contralateral kidney were used for enzyme studies. Statistical analysis was performed using Student's t-test.

Six islet-transplanted rats showed normal weight gain, blood glucose and insulin levels throughout the investigation period (legend Fig. 1). In one rat, however, diabetes recurred for unknown reasons 8 months after islet transplantation. The histological investigations on kidneys from diabetic rats revealed a marked segmental or global enlargement of the glomerular mesangium, thickening of capillary walls, narrowing of the capillary lumina, typical exudative lesions ('caps', 'drop lesions'), and in some cases glomerulocapsular adhesions. On the other hand, islet-transplanted animals demonstrated only age-related glomerular changes. Using light microscopy their glomeruli did not differ from those examined in age-matched normal controls. As reported at the EASD Meeting in 1980 [9], diabetic controls had elevated glucosyltransferase activities compared with normal controls (Fig. 1). Although our data showed relatively wide scatter and overlap between groups, the effect of diabetes was significant $(p<0.02)$. In contrast, islet-transplanted rats had low enzyme levels. Their group mean value dif * fered significantly from that in diabetic controls.

Our results confirm recent findings that streptozotocin-induced diabetes mellitus in rats is followed by an elevated kidney collagen 